\title{
Epidemiology, clinical characteristics, outcome, morbidity and mortality in acromegaly based on the Spanish Acromegaly Registry (Registro Español de Acromegalia, REA)
}

\author{
Antonio Mestrón $^{1}$, Susan M Webb ${ }^{2}$, Ricardo Astorga ${ }^{3}$, Pedro Benito ${ }^{4}$, Miguel Catalá ${ }^{5}$, Sonia Gaztambide ${ }^{6}$, \\ José-Manuel Gómez ${ }^{7}$, Irene Halperín ${ }^{8}$, Tomás Lucas-Morante ${ }^{9}$, Basilio Moreno ${ }^{10}$, Gabriel Obiols ${ }^{11}$, \\ Pedro de Pablos ${ }^{12}$, Concha Páramo ${ }^{13}$, Antonio Picó ${ }^{14}$, Elena Torres ${ }^{15}$, César Varela ${ }^{16}$, José-Antonio Vázquez ${ }^{6}$, \\ Juana Zamora $^{17}$, Mercè Albareda ${ }^{1}$ and Montserrat Gilabert ${ }^{18}$ on behalf of all the REA participants \\ ${ }^{1}$ Department of Endocrinology, Hospital Dos de Maig, Barcelona, ${ }^{2}$ Department of Endocrinology, Hospital Sant Pau, Autonomous University of Barcelona, \\ Barcelona, ${ }^{3}$ Department of Endocrinology, Hospital Virgen del Rocío, Sevilla, ${ }^{4}$ Department of Endocrinology, Reina Sofía Hospital, University of Córdoba, \\ Córdoba, ${ }^{5}$ Department of Endocrinology. Hospital Clínico, Valencia, ${ }^{6}$ Department of Endocrinology, Hospital de Cruces, Bilbao, ${ }^{7}$ Department of \\ Endocrinology, Hospital de Bellvitge, University of Barcelona, Barcelona, ${ }^{8}$ Department of Endocrinology, Hospital Clínic, Universitat de Barcelona, \\ Barcelona, ${ }^{9}$ Department of Endocrinology. Hospital Universitario Puerta de Hierro, Universidad Autónoma de Madrid, Madrid, ${ }^{10}$ Department of \\ Endocrinology, Hospital Gregorio Marañón, Madrid, ${ }^{11}$ Department of Endocrinology, Hospital General Universitari Vall d'Hebron, Barcelona, \\ ${ }^{12}$ Department of Endocrinology, Hospital Juan Negrín, Las Palmas de Gran Canaria, ${ }^{13}$ Department of Endocrinology, Complexo Hospitalario Universitario \\ Xeral-Cíes, Vigo, ${ }^{14}$ Service of Endocrinology and Nutrition, University Hospital of Alicante, Miguel Hernández University, Alicante, ${ }^{15}$ Department of \\ Endocrinology, Hospital Clínico San Cecilio, Granada, ${ }^{16}$ Service of Endocrinology, Hospital Ramón y Cajal, Madrid, ${ }^{17}$ Remote Data Entry System SL, \\ Barcelona and ${ }^{18}$ Medical Department, Oncology Unit, Novartis Farmacéutica, Barcelona, Spain
}

(Correspondence should be addressed to Susan M Webb, Department of Endocrinology, Hospital Sant Pau, Autonomous University of Barcelona, Pare Claret 167,08025-Barcelona, Spain; Email: swebb@hsp.santpau.es)

(A Mestrón and S M Webb have contributed equally to this manuscript)

\begin{abstract}
Objective: To undertake a multicentre epidemiological study reflecting acromegaly in Spain. Design: Voluntary reporting of data on patients with acromegaly to an online database, by the managing physician.

Methods: Data on demographics, diagnosis, estimated date of initial symptoms and diagnosis, pituitary imaging, visual fields, GH and IGF-I concentrations (requested locally), medical, radiotherapy and neurosurgical treatments, morbidity and mortality were collected.

Results: Data were included for 1219 patients (60.8\% women) with a mean age at diagnosis of 45 years (S.D. 14 years). Reporting was maximal in 1997 (2.1 cases per million inhabitants (c.p.m.) per year); prevalence was globally 36 c.p.m., but varied between 15.7 and 75.8 c.p.m. in different regions. Of 1196 pituitary tumours, most were macroadenomas $(73 \%) ; 81 \%$ of these patients underwent surgery, $45 \%$ received radiotherapy and $65 \%$ were given medical treatment (somatostatin analogues in $68.3 \%$ and dopamine agonists in $31.4 \%$ ). Cures (GH values (basal or after an oral glucose tolerance test $<2 \mathrm{ng} / \mathrm{ml}$, normal IGF-I, or both) were observed in $40.3 \%$ after surgery and $28.2 \%$ after radiotherapy. Hypertension (39.1\%), diabetes mellitus $(37.6 \%)$, hypopituitarism $(25.7 \%)$, goitre $(22.4 \%)$, carpal tunnel syndrome $(18.7 \%)$ and sleep apnoea $(13.2 \%)$ were reported as most frequent morbidities; $6.8 \%$ of the patients had cancer (breast in $3.1 \%$ of the women and colon in $1.2 \%$ of the cohort). Fifty-six patients died at a mean age of 60 years (s.D. 14 years), most commonly of a cardiovascular cause (39.4\%); mortality was greater in patients given radiotherapy (hazard ratio 2.29; $95 \%$ confidence interval 1.03 to $5.08 ; P=0.026$ ), and in those in whom GH and IGF-I concentrations were never normal $(P<0.001)$.

Conclusions: This acromegaly registry offers a realistic overview of the epidemiological characteristics, treatment outcome and morbidity of acromegaly in Spain. As active disease and treatment with radiotherapy are associated with an increase in mortality, efforts to control the disease early are desirable.
\end{abstract}

European Journal of Endocrinology $151439-446$

\section{Introduction}

Acromegaly is a rare disease, with an estimated prevalence of around 69 cases per million inhabitants (c.p.m.) (1-5); this precludes the possibility of obtaining, from single reference centres, relevant data on disease incidence, prevalence, morbidity and mortality, and the comparison of different therapeutic options and outcome. Some of these limitations may be overcome by analysing national acromegaly registries; however, these registers, which depend on the voluntary reporting of cases by all the endocrinologists involved, also 
have the limitation that it is not known how complete they really are.

The Spanish Acromegaly Registry (Registro Español de Acromegalia, REA) was set up in 1997 by the Spanish Society of Endocrinology and Nutrition, aimed at registering incident cases of acromegaly and as many cases as possible retrospectively, to analyse the incidence, prevalence, morbidity, mortality and treatment of this disease in Spain.

The aim of this report is to present a multicentre epidemiological study, larger than any previous studies in this country, of pituitary growth hormone (GH) hypersecretion in Spain, to determine clinical characteristics, treatment outcome, morbidity and mortality from which conclusions relevant to clinical practice may be drawn.

\section{Patients and methods}

The intended aim was to register all patients diagnosed as suffering from acromegaly in Spain since 1997, both prospectively and retrospectively (which comprised $90.3 \%$ of the cases); in this latter case, a minimum of available data were required to be included. A specific committee of endocrinologists designed the initial database and periodically analysed the available data. Sponsorship was provided by an unrestricted grant from Novartis Pharma, Barcelona, Spain. Patients were included voluntarily by the managing Spanish physician, who obtained an access password to enter the online web page database. The reporting physician was able to update follow-up data periodically; $70 \%$ of the patients have at least one update after inclusion into the database. During the first 2 years and if the physician had no access to the online forms, patients' data were reported on completed printed forms by hand and sent to the central database company (RDES, SL), where the data were introduced manually into the registry. $\mathrm{GH}$ and insulin-like growth factor (IGF)-I measurements were those ordered locally by each physician and reported from the case notes. The following were collected: patients' demographics, diagnosis (acromegaly, gigantism or ectopic growth hormone-releasing hormone (GHRH) secretion), estimated date of initial symptoms and diagnosis, pituitary imaging (magnetic resonance imaging or computed tomography scan with date and result: tumour size and extension, empty sella or other specified findings initially or tumour remains, postoperative changes or other findings after treatment), visual fields, hormonal data (initial or follow-up GH, basal and after oral glucose tolerance test (OGTT), IGF-I concentration and an indication of whether it was normal or not with respect to the local reference values), and details on treatment; periods of medical treatment (dopaminergic drugs or somatostatin analogues), date, method and dose of radiotherapy, dates and routes of surgical treatment(s), morbidity related to the disease itself or to the treatment (gallstones, osteoarthritis, obstructive sleep apnoea, visual defects, goitre, headache, hypopituitarism, diabetes mellitus or glucose intolerance, carpal tunnel syndrome, high blood pressure, neoplasms with specification of their nature, or others, with an indication of the year of appearance), and mortality (date, cause and whether it was a direct or indirect notification). No detailed diagnostic criteria were given for the different co-morbidities, which were reported on a checklist by the reporting physician.

Patients gave signed informed consent for their data to be included in the database. Data were entered on an SQL Server v6.5 and the web was programmed on Active Server Pages. Each investigator only has access to their own patients, and the security measures of the system do not allow unauthorized access by third parties, in accordance with the Spanish data protection laws. An endocrinologist is the database manager; they, together with the central database handling firm, are the only persons who have access to the complete database. Data are analysed periodically by the database manager using SAS 8.2 software on an SQL database. Possible inconsistencies and missing data are identified and queries sent to the reporting investigators for completion.

\section{Cure}

When the database was established in 1997, criteria for cure were considered to be: GH after OGTT $<2 \mathrm{ng} / \mathrm{ml}$ $(\mu \mathrm{g} / \mathrm{l})$ and normal age- and sex-matched IGF-I concentrations; however, if a patient met only one of these criteria (and the other was missing), or a basal GH $<2 \mathrm{ng} / \mathrm{ml}$ was reported, they were also included in the cured group. These criteria were maintained as initially agreed, although they have been modified since (6). It should also be remembered that $\mathrm{GH}$ and IGF-I assays have changed over the years; more recent determinations using more sensitive immunoradiometric assays are difficult to compare with older polyclonal radioimmunoassays. Furthermore, conversion factors between SI units and metric measurements for $\mathrm{GH}$ have also changed over the years $(1 \mathrm{ng} / \mathrm{ml}$ used to be deemed equivalent to $2 \mathrm{mIU} / \mathrm{l}$ in the $1980 \mathrm{~s}$, but more recently this has changed to 2.6 or $3 \mathrm{mIU} / \mathrm{l}$ ). Each reporting physician indicated if $\mathrm{GH}$ and IGF-I were normal or not according to these criteria and the local reference values.

\section{Statistics}

Results are expressed as mean \pm 2 s.D. in the case of normally distributed data, and as median plus range in non-normally distributed data. The Weibull model for survival data, obtained using the stepwise method, was used to analyse the deaths; the statistical hazard ratio is given for variables included in this model. Differences between proportions are presented as the 95\% confidence interval (CI) (7). A $P$ value $<0.05$ 
was considered statistically significant. In order to identify features related to survival after radiotherapy, a multivariate analysis was used. A Weibull model for survival data was obtained that included only patients treated with radiotherapy; in this case the backward method was used to identify significant differences.

All the statistical analyses were carried out using the statistical package SAS v8.2.

\section{Results}

\section{Population}

By January 2004, 1219 patients were included in the analysis: 478 (39.2\%) men and 741 (60.8\%) women, with a mean age at diagnosis of 45 years (S.D. 14 years) (Table 1).

Prevalence and incidence The prevalence of GH hypersecretion was 33.7 c.p.m., based on the last population census in Spain (8). However, large differences between the regions were identified: there were three Autonomous Communities (Aragón, Asturias and La Rioja), which in total represent 2.5 million inhabitants, in which there were no reported cases; excluding these areas, the prevalence was 36 c.p.m. Reporting was maximal in the year after the database was set up (2.1 new c.p.m. in 1997), whereas the patients' estimates of the year in which symptoms began was around 5 years before diagnosis.

\section{Aetiology}

The most common cause of acromegaly was a pituitary tumour $(n=1196$ : 842 macroadenomas $(>10 \mathrm{~mm}$ in

Table 1 Number and percentage of acromegalic patients reported from each Spanish Autonomous Community (by January 2004), and prevalence calculated from the last available population census in Spain (dated 2001).

\begin{tabular}{lrrc}
\hline Autonomous community & \multicolumn{1}{c}{$\boldsymbol{n}$} & \multicolumn{1}{c}{$\%$} & Prevalence 2004 \\
\hline Andalusia & 168 & 13.8 & 27.4 \\
Balearic Isles & 16 & 1.3 & 16.9 \\
Community of Madrid & 255 & 20.9 & 53.9 \\
Community of Murcia & 29 & 2.4 & 26.0 \\
Community of Valencia & 101 & 8.3 & 23.2 \\
Canary Islands & 33 & 2.7 & 15.7 \\
Cantabria & 33 & 2.7 & 56.5 \\
Castilla-La Mancha & 23 & 1.9 & 15.6 \\
Castilla-León & 87 & 7.1 & 37.8 \\
Catalonia & 270 & 22.2 & 46.6 \\
Basque Country & 85 & 7.0 & 75.8 \\
Extremadura & 17 & 1.4 & 16.6 \\
Galicia & 61 & 5.0 & 21.9 \\
Navarre & 41 & 3.4 & 66.2 \\
Total & 1219 & 100.0 & 33.7 \\
Total 2* & & & 36.2 \\
\end{tabular}

* Excluding the Communities of Aragon, La Rioja and Asturias for which there were no reports. diameter) compared with 314 microadenomas; in 40 cases the tumour size was not recorded). In eight cases, GH hypersecretion was attributable to ectopic GHRH secretion; in the remaining 15 aetiology was not reported. Acromegaly was present in $97.3 \%$ of patients and pituitary gigantism in $2.2 \%$ of the reported cases. In six cases $(0.5 \%)$ the clinical presentation was not specified. Three patients suffered from multiple endocrine neoplasia type 1 .

\section{Treatment}

Eighty-one percent (995 of 1219) of the patients underwent surgery at least once, most commonly by the transsphenoidal route (Table 2). Only in the minority of patients who required a third $(n=15)$ or even a fourth $(n=4)$ operation was the transcranial route more frequently used. Forty-five percent of the patients included (543) underwent radiotherapy, most commonly conventional $(n=504 ; 92.7 \%)$, with a few cases of fractionated stereotaxic radiotherapy $(n=27$; $5 \%)$ or radiosurgery $(n=9 ; 1.7 \%)$; in three $(0.6 \%)$ the irradiation technique was not specified. In 318 patients $(58.6 \%)$, irradiation was performed before 1991, 221 patients $(40.7 \%)$ underwent radiotherapy since 1992 , and for four patients $(0.7 \%)$ the date of radiotherapy was not reported. At the time of the latest report on the database, $153(28.2 \%)$ of those who had undergone radiotherapy were considered cured. Time elapsed between radiotherapy and cure was up to 5 years in $18.1 \%(n=90)$, up to 10 years in a further $5.8 \%(n=29$ patients $)$, up to 15 years in another $4.4 \%(n=22)$ and more than 20 years in $2.4 \%(n=12)$. Medical treatment was used in $65 \%$ of cases, most commonly somatostatin analogues ( $n=540 ; 68.3 \%$ ), followed by dopamine agonists $(n=248 ; 31.4 \%)$, especially in the patients treated before the early 1990s. Before 1990, just 199 patients (25\%) received medical treatment, whereas since then the percentage has inceased to $75 \%(n=584)$. The commercial availability of lanreotide since 1994, and soon after of octreotide-LAR, in Spain explain this increase, and probably also the decline in the use of radiotherapy.

\section{Treatment outcome}

Postoperative evaluations were available for 995 patients who underwent surgery; in 124 patients, the immediate postoperative outcome could not be determined because GH and IGF-I values were not provided $(n=112)$ or the date of the blood tests was missing $(n=12)$, making it unclear whether they corresponded to a pre- or postoperative evaluation. Of the remaining 871 patients, $351(40.3 \%)$ were considered cured and $520(59.7 \%)$ uncured. The classification as cured was based on the classical criteria (post-OGTT GH $<2 \mathrm{ng} / \mathrm{ml}$ and normal IGF-I values) in $72.6 \%$ of the 
Table 2 Treatments received by the acromegalic patients.

\begin{tabular}{|c|c|c|c|c|c|c|c|c|}
\hline \multirow[b]{2}{*}{ Treatment } & \multicolumn{2}{|c|}{ Patients } & \multicolumn{2}{|c|}{ Cured } & \multicolumn{2}{|c|}{ Not cured } & \multicolumn{2}{|c|}{ Data missing } \\
\hline & $n$ & $\%$ & $n$ & $\%$ & $n$ & $\%$ & $n$ & $\%$ \\
\hline Surgery, radiotherapy and drugs & 359 & 29.4 & 98 & 27.3 & 260 & 72.4 & 1 & 0.3 \\
\hline Surgery and drugs & 277 & 22.6 & 99 & 35.7 & 178 & 64.3 & 0 & 0 \\
\hline Surgery & 246 & 20.1 & 114 & 46.3 & 48 & 19.5 & 84 & 34.2 \\
\hline Drugs & 113 & 9.3 & 8 & 7.1 & 105 & 92.9 & 0 & 0 \\
\hline Surgery and radiotherapy & 113 & 9.3 & 40 & 35.4 & 34 & 30.1 & 39 & 34.5 \\
\hline Radiotherapy and drugs & 42 & 3.5 & 5 & 11.9 & 37 & 88.1 & 0 & 0 \\
\hline Radiotherapy & 29 & 2.4 & 10 & 34.5 & 13 & 44.8 & 6 & 20.7 \\
\hline Treatment unknown & 28 & 2.4 & 2 & 7.1 & 24 & 85.8 & 2 & 7.1 \\
\hline No treatment & 9 & 0.7 & 0 & 0 & 8 & 88.9 & 1 & 11.1 \\
\hline Lost to follow-up & 2 & 0.2 & 0 & 0 & 0 & 0 & 2 & 100 \\
\hline No treatment: spontaneous remission & 1 & 0.1 & 1 & 100 & 0 & 0 & 0 & 0 \\
\hline Total & 1219 & 100.0 & 377 & 30.9 & 707 & 58.0 & 135 & 11.1 \\
\hline
\end{tabular}

patients; $17.7 \%$ only had normal IGF-I (with no available $\mathrm{GH}$ values); in $3.7 \%$ basal $\mathrm{GH}$ or post-OGTT $\mathrm{GH}$, or both, were $<2 \mathrm{ng} / \mathrm{ml}$ but IGF-I values were unavailable; and in $2 \%$, basal $\mathrm{GH}$ was $<2 \mathrm{ng} / \mathrm{ml}$ with normal IGF-I. Cure rates differed considerably between the reporting hospitals (which were not necessarily where the patients had been operated on), being greatest (between 57.8 and $65.4 \%$ ) in three large reference centres (responsible for $21.2 \%$ of the reported patients), but being $0 \%$ in some units.

Among non-operated patients, the number of cures was low $(25 / 224,11.2 \%$ : eight treated with drugs, 10 treated with radiotherapy alone, five treated with radiotherapy and drugs; for two, data were missing). Of these, cure was judged on the classical criteria (post-OGTT GH $<2 \mathrm{ng} / \mathrm{ml}$ and normal IGF-I) in 21, three only had normal IGF-I (with no available GH data) and, for the remaining one, GH after OGTT was $>2 \mathrm{ng} / \mathrm{ml}$, but IGF-I data were unavailable. In nine patients, insufficient GH/IGF-I information precluded classification as cured or not-cured; 105 of the not-cured patients received drugs alone, 37 received radiotherapy and drugs, 13 received radiotherapy alone, 8 received no treatment, and in 27 no data were available.

\section{Morbidity}

Associated morbidity is shown in Table 3. Hypertension, diabetes mellitus, hypopituitarism, goitre, carpal tunnel syndrome and sleep apnoea were most frequently reported. Ninety malignant neoplasms were identified (6.8\% of patients), most commonly breast and colon cancer (Table 4). In five patients, at least two malignant tumours were detected during follow-up.

Compared with those who were never exposed to somatostatin analogues, patients who were treated with these drugs had more diabetes mellitus (42\% compared with $33.5 \%$; 95\% CI 2.7 to $14.3 ; P=0.005)$, gallstones (15.5\% compared with $4.1 \%$; 95\% CI 7.7 to $15.3 ; P<0.001)$, sleep apnoea $(16.3 \%$ compared
Table 3 Morbidity (includes only those patients in whom the presence or absence of morbidity was reported).

\begin{tabular}{lcc}
\hline Disease & Prevalence (\%) & Reported cases \\
\hline Diabetes & 37.6 & $394 / 1049$ \\
Hypertension & 39.1 & $405 / 1036$ \\
Dyslipidaemia & 25.8 & $120 / 465$ \\
Arthropathy & 19.6 & $92 / 470$ \\
Carpal tunnel syndrome & 18.7 & $184 / 983$ \\
Goitre & 22.4 & $225 / 1005$ \\
Sleep apnoea & 13.2 & $117 / 886$ \\
Cerebrovascular disease & 7.1 & $34 / 476$ \\
Cardiovascular disease & 14.1 & $69 / 488$ \\
Chronic lung disease & 4.9 & $23 / 465$ \\
Hypopituitarism & 25.7 & $237 / 922$ \\
Gallstones & 9.5 & $90 / 949$ \\
\hline
\end{tabular}

with $10.5 \%$; $95 \%$ CI 1.3 to $10.4 ; P=00.013)$ and colon polyps (13.9\% compared with $7.5 \%$; $95 \%$ CI 0.5 to $12.4 ; P=0.034)$.

\section{Mortality}

Fifty-six patients are known to have died, at a median age of 60 years (range 26-84 years). The most common cause of death was cardiovascular (Table 5). Of these, $32(57.1 \%)$ had undergone radiotherapy, whereas 19 (33.9\%) had not; for the remaining five, information on radiotherapy was missing. Patients who died had a twice greater probability of having been treated with radiotherapy than those who survived (hazard ratio of $2.29 ; 95 \%$ CI 1.03 to 5.08 ; $P=0.026$ ). A multivariate analysis (which included tumour size, presence or not of diabetes, age when radiotherapy was administered, high blood pressure, attainment of normal IGF-I concentration after treatment, presence or not of associated cancer or cardiovascular disease, and time elapsed between diagnosis of acromegaly and last follow-up) performed to identify parameters related to death in patients given radiotherapy, failed to identify any significant features; however, the backward method revealed that the most relevant 
Table 4 Neoplasms in acromegaly. Prevalence is calculated from the total registry of 1219 cases.

\begin{tabular}{llr}
\hline & Prevalence (\%) & $\boldsymbol{n}$ \\
\hline Cancers & & \\
Breast & $1.8\left(3.1^{*}\right)$ & 23 \\
Colon & 1.2 & 15 \\
Lung & 0.4 & 5 \\
Gastric & 0.3 & 4 \\
Other malignant & 3.5 & 43 \\
$\quad$ neoplasms† & & \\
Patients with malignant & 7.5 & \\
$\quad$ neoplasms & & \\
Benign neoplasms & & \\
$\quad$ Colon polyps & $9.5 \ddagger$ & \\
$\quad$ Other benign neoplasias§ & 2.0 & 49 \\
Other neoplasias & 0.3 & \\
$\quad$ (not classified, & & \\
$\quad$ malignant/benign) & &
\end{tabular}

* Women alone.

†Included the following cancers: bladder (6), skin (3), ovarian (3), cervix adenocarcinoma (2), lymphoma (2), kidney (2), parotid (2), endometrial (2), cerebral (7), eye (1), pancreas (1), pleural (1), testicular (1), thyroid (2), neurinomatosis (1), reticulosarcoma (1), adenocarcinoma not otherwise specified (1), liver (1), dermatofibrosarcoma (1), melanoma (1), carcinoid (1) and scrotal (1).

fOnly patients in whom colonoscopy was performed are included.

§Included: meningioma (5), uterine leiomioma (3), prostatic adenoma (3), benign ovarian neoplasia (3), other fibromatosis (3), benign neoplasia not otherwise specified (2), benign bone tumour (1), vocal cord polyps (1), breast cyst (1), thyroid follicular adenoma (1).

factor related to probability of dying after radiotherapy was longer time between diagnosis and last follow-up (associated with older age). Normalization of IGF-I concentration did not attain statistical significance in relation to survival after radiotherapy; however, of all the other features analysed it was the only one that showed a trend.

Mortality was also clearly greater in patients who had never achieved a basal GH (51 compared with five deaths; $95 \%$ CI 0.039 to 0.193 ; $P<0.001$ ) or a post-OGTT GH $<2 \mathrm{ng} / \mathrm{ml}$ (48 compared with eight deaths; $95 \%$ CI 0.074 to 0.257 ; $P<0.001$ ), most frequently from a cardiovascular cause. Similarly, if IGF-I had never been normal, mortality was also greater (41 compared with 15 deaths; $95 \%$ CI 0.170 to 0.396 ; $P=0.001)$. No correlation of mortality with hypopituitarism, greater reported IGF-I values or date of treatment (before or since 1991) was observed. More patients never treated with somatostatin analogues died than among those exposed at some stage to this medical treatment (37 compared with 19; 95\% CI 0.229 to $0.470 ; P=0.016$ ) (Table 5).

\section{Discussion \\ Demography}

The mean age of the acromegalic patients at diagnosis (45 years) did not differ from those reported in previous series from other countries $(41-48$ years $(2,9-12))$. However, there was a female predominance that has otherwise been reported only in an epidemiological study of a small Spanish population in the Basque Country ( $n=74$ with $65 \%$ females) (3), and in the recently presented West Midlands Acromegaly database ( $n=419 ; 57.5 \%$ females) (12). Two further Spanish studies of acromegaly also showed a female predominance, although these were not epidemiological studies $(13,14)$. In contrast, Beauregard et al. (11) reported more males $(58 \%)$ than females.

Prevalence and reported incidence The global prevalence of 36 c.p.m. varied between regions, reflecting differences in the level of reporting in the various Spanish Autonomous Communities and the existence of referral hospitals that receive patients from neighbouring areas for operation, treatment or for follow-up. In areas with a high reporting index and a large population (Basque Country, Navarre, Madrid, Catalunya and Cantabria), the prevalence varied between 46 and 75 c.p.m. Previous reports on smaller populations recorded a prevalence of between 38 and 69 c.p.m. $(1-5,15)$. A recent study from Finland, where all patients are cared for in five teaching hospitals, revealed a globally greater prevalence of 120 c.p.m. (10). Reporting was maximal in 1997 when the database was set up, most probably reflecting initial reporting enthusiasm by all participants.

Treatment outcome The low surgical cure rate (40.3\%) compared with that reported in prestigious reference neurosurgical centres $(11,16-23)$ is probably a closer to that encountered in clinical practice, as less experienced neurosurgical centres rarely publish their results (23-25); the cure rate increased to $60 \%$ in

Table 5 Mortality among patients with acromegaly who were treated or not treated with somatostatin analogues (SSa).

\begin{tabular}{|c|c|c|c|c|c|}
\hline Cause of death & $n$ & $\%$ & $\%$ (excluding unknown) & Treated with SSa & Not treated with SSa \\
\hline Data missing & 15 & 26.8 & - & 6 & 9 \\
\hline Unknown & 3 & 5.4 & - & 0 & 3 \\
\hline Cardiovascular disease & 15 & 26.8 & 39.4 & 4 & 11 \\
\hline Cerebrovascular disease & 5 & 8.9 & 13.2 & 1 & 4 \\
\hline Respiratory disease & 3 & 5.4 & 7.9 & 2 & 1 \\
\hline Malignant disease & 9 & 16.1 & 23.7 & 3 & 6 \\
\hline Other & 6 & 10.6 & 15.8 & 3 & 3 \\
\hline Total & 56 & 100.0 & 100.0 & 19 & 37 \\
\hline
\end{tabular}


large experienced hospitals. Even in published series, cure rates vary tremendously and an inverse correlation has been found between the number of neurosurgeons operating in one centre and the cure rate $(23,26)$, varying between $37 \%$ and $91 \%$ for microadenomas $(20,27)$. More patients underwent radiotherapy before 1991 once somatostatin analogues became available.

\section{Morbidity}

Associated morbidity was that reported by the physician and, given the observational nature of the registry, is probably underestimated, as not all patients underwent all the tests necessary for a systematic elimination of these diseases; thus, the reported prevalence should be considered a minimum. The previously reported prevalence of hypertension in acromegalic patients is around $35 \%$, but varies widely - between $18 \%$ and $60 \%$ (28) - as a result of the different criteria used to define and to measure hypertension, and the lack of adjustment for sex, age, ethnicity, etc. Hypertension was found to be more prevalent in those acromegalic patients with high IGF-I concentrations than in the total acromegalic or normal populations (9). The prevalence of hypertension in this registry was not affected by the treatment or lack of treatment with somatostatin analogues. Diabetes mellitus is more prevalent in acromegaly than in the general population, greater in the Spanish acromegalic population (especially in those exposed to somatostatin analogues) than in New Zealand (20\%) (4), but lower than in Canada (40\% plus 22\% glucose intolerance) (11).

The sleep apnoea syndrome reportedly affects between $67 \%$ and $75 \%$ of acromegalic patients when investigated prospectively $(29,30)$. This is much greater than the prevalence of $13 \%$ observed in our registry and presumably reflects a low awareness of the problem by many physicians, who do not specifically ask about snoring and sleep apnoea in all their acromegalic patients. It was more frequent in those treated with somatostatin analogues, probably reflecting both a more active disease and lower postoperative cure rate than in those who had not required medical treatment, and further awareness of the problem in the past decade when these analogues became available.

Increased cancer risk in patients with acromegaly has long been debated (31-33). Data indicate that, even though the incidence of malignancy is not necessarily greater, the overall mortality rate and that from colon cancer, cardiovascular disease and all malignant disease are increased in active acromegaly, but not if post-treatment $\mathrm{GH}$ concentrations are less than $2.5 \mu \mathrm{g} / \mathrm{l}(33,34)$. For bronchial and breast cancer, the correlation is not so clear (34-36). Colon polyps (which may precede the development of colon cancer) do seem to be increased in acromegaly (32), and were more frequent in our patients who had more active disease and required somatostatin analogues at some stage. With the improvement in the management of acromegaly, more patients will reach ages at which cancer incidence increases, and it will be important in the future to compare results from acromegalic patients with those of age-matched populations. Colorectal cancer has been reported in about 1\% of acromegalic patients, and prevalence in our population was similar $(1.2 \%)$, as also were the prevalences of breast cancer $(3.1 \%)$ and bronchial cancer $(0.4 \%)$ (35-38). Colonoscopic examinations were not carried out systematically in all patients in this observational registry, which explains the low prevalence of colon polyps identified $(9.5 \%)$, in comparison with studies in which all patients underwent pancolonoscopy prospectively $(9-40 \%)(32)$.

\section{Mortality}

Evaluation of mortality in acromegaly series is problematic, because the numbers of patients are small with large confidence intervals, the patterns of death are changing in the general population, types of $\mathrm{GH}$ sampling and standards of GH/IGF-I assays have changed over the years, and IGF-I values are not always calibrated for age or sex. Nevertheless, a last high GH concentration has been reported to be associated with increased mortality in acromegaly in different series $(9,10,12,34,35)$, in addition to a high IGF-I (4, $11,18)$. Orme et al. (35) did not observe an increased Standard Mortality Ratio (SMR) in acromegalic patients when GH post-treatment was less than $2.5 \mathrm{ng} / \mathrm{ml}$ whereas, above $10 \mathrm{ng} / \mathrm{ml}$, SMR increased to 4.6 . In the study by Swearingen (18) no differences in mortality of operated patients were observed in those patients considered cured $(\mathrm{GH}<2.5 \mathrm{ng} / \mathrm{ml}$ or normal IGF-I, or both) when compared with the general population. If the disease was active, SMR was greater, at 1.8. A recent Canadian study on mortality in 99 acromegalic patients followed long-term showed no difference in mortality if they were in remission (random $\mathrm{GH}<2.5 \mu \mathrm{g} / \mathrm{l}$, or $\mathrm{GH}$ after OGTT $<1 \mu \mathrm{g} / \mathrm{l}$ and IGF-I within the normal range; five of 57 patients, $9 \%$ ), but was significantly increased in those with persistent disease $(38 \%, P=0.008)$, when compared with the normal population (11). A recent study from the West Midlands of England, however, revealed a correlation of increased mortality with a high post-treatment GH concentration ( $>4 \mathrm{mU} / \mathrm{l}, \mathrm{SMR} 1.31$; $95 \% \mathrm{CI}$ 1.03 to $1.66 ; P=0.05)$, and also after radiotherapy (SMR 1.7, 95\% CI 1.13 to 2.65; $P<0.05$ ), mainly from cerebrovascular disease (SMR 4.42, 95\% CI 2.71 to $7.22 ; P=0.005)$, which therefore appears to be deleterious. However, there was no correlation with increased post-treatment IGF-I concentrations (available in $86 \%$ of the patients) (12). In that study conducted over 13 years in 419 acromegalic patients, of whom $61 \%$ underwent surgical treatment and 50\% 
radiotherapy, 95 died, giving an SMR of 1.26 (95\% CI 1.03 to 1.54 ). Our registry confirms that radiotherapy and lack of reported normal GH or IGF-I values were associated with a greater risk of mortality, but hypopituitarism requiring any substitution therapy was not.

Mean age at death in the Spanish registry was 60 years, the same as in New Zealand (61 years) (39, 40 ), but older than in Canada (42 years) (11). The known causes of death in this series are similar to those previously reported in the large retrospective British study on 1362 patients (35), in which the main cause was cardiovascular, accounting for $36.6 \%$ of the deaths, similar to our $39.4 \%$; this was followed by cancer $(22.7 \%)$, also comparable to our $23.7 \%$ of deaths. Given the nature of the registry and the Spanish data protection laws, it was not possible to confirm centrally whether the patients included in the registry were dead or alive after the last report sent in to the database by the physician; thus SMR could not be calculated because it will always be underestimated.

In conclusion, although this acromegaly registry lacks the precision of other large series homogeneously followed in one centre, it offers a realistic overview of the epidemiological characteristics, treatment outcome, morbidity and mortality of acromegaly in Spain, and confirms that active disease and treatment with radiotherapy are associated with an increased mortality; thus efforts to control the disease early (i.e. in experienced neurosurgical centres) are desirable.

\section{Acknowledgements}

The support of the Spanish Society for Endocrinology and Nutrition (S.E.E.N), an unrestricted grant from Novartis Pharma, Barcelona, Spain and the submissions by all participating endocrinologists are gratefully acknowledged.

The following REA participants contributed to this work: Miguel Aguirre Sánchez-Covisa, Ma Mercè Albareda Riera, Marisol Alcaraz Tafalla, Isabel Alonso Troncoso, Cristina Álvarez Escolà, Victor Manuel Andía Melero, Alfonso Arranz Martín, Luis Arribas Palomar, María Ballesteros Pomar, Juan José Beitia Martín, Pedro Benito López, Ignacio Bernabeu Morón, Concepción Blanco Carrera, Benito Blanco Samper, Mauro Boronat Cortés, Maria José Carrera Santaliestra, Luis Castillo López, Miguel Catalá Bauset, Mํㅡㄹ del Mar Cordero Diez, Enrique Costilla Martín, M $M^{\underline{a}}$ Victoria Cózar León, Guillem Cuatrecasas Cambra, Daniel Antonio De Luís Román, Ma Paz de Miguel Novoa, Pedro De Pablos Velasco, Carlos Del Pozo Picó, Juan José Diez Gómez, Alberto Díez Hernández, Alejandra Durán Rodríguez-Hervada, Isabel Esteva de Antonio, Carmen Fajardo Montañana, Lluís Forga Llenas, Ángel Luis Fraile Saez, M ${ }^{\mathrm{a}}$ Angeles Galvez Moreno, José Andrés García Centera, Manuel Gargallo Fernández, Inmaculada Gavilán Villarejo, Sonia Gaztambide, Paloma Gil del Álamo, Alberto Gilsanz Peral, Antonio Gippini
Pérez, Marcelino Gómez Balaguer, Jose Manuel Gómez Saez, Luis Alberto Gómez, Juan José Gorgojo Martínez, Eduardo Guerrero Martínez, Irene Halperin Rabinovich, Juan Angel Hernández Bayo, Antonio Hernández López, Pedro Iglesias, Fátima Illán Gómez, Miguel Ángel Jaunsolo Barranechea, Albert Lecube Torelló, Gaspar Liante Peñambía, Martin López dela Torre Casares, Elena López Hernández, José López López, Antonio López-Guzmán Guzmán, Ana Lucas Martín, Tomás Lucas Morante, Mónica Marazuela Azpiroz, Amparo Marco Martínez, Ángel Luis Marco Mur, Fidel Martin Castillo, Tomás Martín González, Maria Asunció Martínez Brocca, Ana Megia Colet, Juan Francisco Merino Torres, $\mathrm{M}^{\mathrm{a}}$ José Morales Gorría, Francisco Morales Perez, Basilio Moreno Esteban, Jesús Murillo Sanchis, M ${ }^{\mathrm{a}}$ Teresa Muros de Fuentes, Gabriel Obiols, Concepción Páramo Fernández, Isabel Pavón de Paz, Fernando Pazos Toral, Mํㅗ Begoña Pérez Corral, Antonio Pérez Pérez, J Javier Pi Barrio, Gonzalo Piedrola Morato, José M ${ }^{\mathrm{a}}$ Pou Torelló, Victor Puigdevall Gallego, Paloma Rodríguez Guerrero, Azuzena Rodríguez Robles, Enrique Romero Bobillo, Belén Ruano Vieitez, Enrique Ruiz Pérez, Ma Pilar Ruiz-Valdepeñas Herrero, Isabel Salinas i Vert, Juan Salmerón de Diego, Ma Concepción Sanabria Pérez, Petra Sánchez Cernigon, Mercedes Santos Reyero, Ángel Sanz Valtierra, Julia Sastre Marcos, Álvaro Sillero Sánchez, Hipólito Silva Manzano, Joan Soler Ramon, Alfonso Ll Soto Llorens, Mํㅡ́ Ángeles Tapia Herrero, Susana Tenes Rodrigo, $M^{\underline{a}}$ Concepción Terroba Larumbe, Elena Torres Vela, Cesar Varela Da Costa, José Antonio Vázquez García, Juan José Vendrell, Eva Venegas Moreno, Almudena Vicente Delgado, Pablo Vidal-Ríos Vázquez, Lluís Vila Ballester, Mariano Villa Bautista, Carles Villabona Artero, Aurelia Villar Bonet, Susan M Webb and José Zurro Hernández.

\section{References}

1 Ritchie CM, Atkinson AB, Kennedy AL, Lyons AR, Gordon DS, Fannin T \& Hadden DR. Ascertainment and natural history of treated acromegaly in Northern Ireland. Ulster Medical Journal $19905955-62$.

2 Bengtsson BA, Eden S, Ernest I, Oden A \& Sjogren B. Epidemiology and long-term survival in acromegaly. A study of 166 cases diagnosed between 1955 and 1984. Acta Medica Scandinavica $1988223327-335$.

3 Etxabe J, Gaztambide S, Latorre P \& Vázquez JA. Acromegaly: an epidemiological study. Journal of Endocrinological Investigation $199316181-187$.

4 Holdaway IM \& Rajasoorya C. Epidemiology of acromegaly. Pituitary 19992 29-41.

5 Monson JP. The epidemiology of endocrine tumours. EndocrineRelated Cancer 20007 29-36.

6 Giustina A, Barkan A, Casanueva FF, Cavagnini F, Frohman L, Ho K, Veldhuis J, Wass J, Von Werder K \& Melmed S. Criteria of cure of acromegaly. A consensus statement. Journal of Clinical Endocrinology and Metabolism 200085 526-529.

7 O'Fallon JR, Dubey SB, Salsburg DS, Edmonson A \& Soffer T. Should there be statistical guidelines for medical research papers? Biometrics $197834687-695$. 
8 Instituto Nacional de Estadística. INEBASE Censo 2001. www.ine.es

9 Rajasoorya C, Holdaway IM, Wrightson P, Scott DJ \& Ibbertson HK. Determinants of clinical outcome and survival in acromegaly. Clinical Endocrinology 1994 41 95-102.

10 Kauppinen-Markelin RM, Niskanen L, Voutilainen E, Salmela P, Ebeling T, Salmi J, Jaatinen P, Viikari J, Välimäki MJ \& Sane T. Treatment of acromegaly in Finland: a National survey. In Proceedings of the 34th International Symposium on GH and Growth Factors in Endocrinology and Metabolism, Budapest, 2002 Abstract F4.

11 Beauregard C, Truong U, Hardy J \& Serri O. Long-term outcome and mortality after transsphenoidal adenomectomy for acromegaly. Clinical Endocrinology 200358 86-91.

12 Ayuk J, Clayton RN, Holder G, Sheppard MC, Stewart PM \& Bates AS. Growth hormone and pituitary radiotherapy, but not serum insulin-like growth factor-I concentrations, predict excess mortality in patients with acromegaly. Journal of Clinical Endocrinology and Metabolism 200489 1613-1617.

13 del Pozo C, Webb SM, Oliver B, Tresserras P \& de Leiva A. Tratamiento de la acromegalia. Resultados en 56 pacientes. Medicina Clínica 199094 85-87.

14 Barceló B, Pérez C, Davila N, Lucas T, Salto L \& Alcañiz J. Endocrinologic evaluation of 61 patients with acromegaly treated with transsphenoidal removal alone, or associated with telecobalt irradiation or bromocriptine or both. Medicina Clínica $1983 \mathbf{8 0}$ 735-741.

15 Alexander L, Appleton D, Hall R, Ross WM \& Wilkinson R. Epidemiology of acromegaly in the Newcastle region. Clinical Endocrinology $19801271-79$.

16 Osman IA, James RA, Chatterjee S, Mathias D \& Kendall-Taylor P. Factors determining the long-term outcome of surgery for acromegaly. Quarterly Journal of Medicine 199487 617-623.

17 Sheaves R, Jenkins P, Blackburn P, Huneidi AH, Afshar F, Medbak S, Grossman AB, Besser GM \& Wass JAH. Outcome of transsphenoidal surgery for acromegaly using strict criteria for surgical cure. Clinical Endocrinology $1996 \mathbf{4 5} 407-413$.

18 Swearingen B, Barker F, Katznelson L, Biller B, Grinspoon S, Klibanski A, Moayeri N, Black PM \& Zervas NT. Long-term mortality after transsphenoidal surgery and adjunctive therapy for acromegaly. Journal of Clinical Endocrinology and Metabolism 199883 3419-3426.

19 Pardo S, Albareda M, Webb SM, Oliver B \& Bartumeus F. Tratamiento quirúrgico: indicaciones y resultados. In Acromegalia, pp 169-187. Ed. SM Web. Barcelona: Acción Médica, 1998.

20 Ahmed S, Elsheikh M, Stratton IM, Page RC, Adams CB \& Wass JAH. Outcome of transphenoidal surgery for acromegaly and its relationship to surgical experience. Clinical Endocrinology $1999 \mathbf{5 0} 561-567$

21 Lucas Morante T, García-Uría J, Estrada J, Saucedo G, Cabello A. Alcañiz J \& Barceló B. Treatment of invasive growth hormone pituitary adenomas with long-acting somatostatin analog SMS 201-995 before transsphenoidal surgery. Journal of Neurosurgery 199481 10-14.

22 Biermasz N, Van Dulken H \& Roelfsema F. Ten-year follow-up results of transsphenoidal microsurgery in acromegaly. Journal of Clinical Endocrinology and Metabolism 200085 4596-4602.

23 Jenkins D, O’Brien I, Johnson A, Shakespear R, Sheppard MC \& Stewart PM. The Birmingham pituitary database: auditing the outcome of the treatment of acromegaly. Clinical Endocrinology $1995 \mathbf{4 3} 517-522$
24 Yamada S, Aiba T, Takada K, Ozawa Y, Shimizu T, Sawano S, Shishiba Y \& Sano T. Retrospective analysis of long-term surgical results in acromegaly: preoperative and postoperative factors predicting outcome. Clinical Endocrinology 199645 291-298.

25 Lisset CA, Peacey SR, Laing I, Tetlow L, Davis JR \& Shalet SM. The outcome of surgery for acromegaly: the need for a specialist pituitary surgeon for all types of growth hormone secreting adenoma. Clinical Endocrinology $1998 \mathbf{4 9} 653-657$.

26 Gittoes NJ, Johnson AP, Sheppard MC \& Stewart PM. Outcome of surgery for acromegaly: the experience of a single surgeon. Quarterly Journal of Medicine 199992 741-745.

27 Clayton RN, Stewart PM, Shalet SM \& Wass JAH. Pituitary surgery for acromegaly: should be done by specialists. British Medical Journal $1999319588-589$.

28 Bondanelli M, Ambrosio MR \& degli Uberti EC. Pathogenesis and prevalence of hypertension in acromegaly. Pituitary 20014 239-249.

29 Fatti LM, Scacchi M, Pincelli AI, Lavezzi E \& Cavagnini F. Prevalence and pathogenesis of sleep apnea and lung disease in acromegaly. Pituitary $20014259-262$.

30 Weiss V, Sonka K. Pretl M, Dostalova S, Klozar J, Rambousek P, Marek J \& Haas T. Prevalence of the sleep apnea syndrome in acromegaly population. Journal of Endocrinological Investigation 200023 515-519.

31 Melmed S. Acromegaly and cancer: not a problem? Journal of Clinical Endocrinology and Metabolism $2001862929-2934$.

32 Jenkins PJ \& Besser M. Clinical perspective: acromegaly and cancer: a problem. Journal of Clinical Endocrinology and Metabolism $2001862935-2941$.

33 Webb SM, Casanueva FF \& Wass JAH. Oncological complications of excess GH in acromegaly. Pituitary 20025 21-25.

34 Bates AS, Van't Hoff W, Jones JM \& Clayton RN. An audit of outcome of treatment in acromegaly. Quarterly Journal of Medicine $199386293-299$.

35 Orme SM, McNally RJ, Cartwright RA \& Belchetz PE. Mortality and cancer incidence in acromegaly: a retrospective cohort study. United Kingdom Acromegaly Study Group. Journal of Clinical Endocrinology and Metabolism 199883 2730-2734.

36 Nabarro JD. Acromegaly. Clinical Endocrinology $1987 \quad 26$ $481-512$.

37 Ron E, Gridley G, Hrubec Z, Page W, Arora S \& Fraumeni JF. Acromegaly and gastrointestinal cancer. Cancer $1991 \mathbf{6 8}$ $1673-1677$.

38 Popovic V, Damjanovic S, Micic D, Nesovic M, Djurovic M, Petakov M, Obradovic S, Zoric S, Simic M, Penezic Z \& Marinkovic J. Increased incidence of neoplasia in patients with pituitary adenomas. The Pituitary Study Group. Clinical Endocrinology $1998 \mathbf{4 9}$ $441-445$.

39 Holdaway IM, Rajasoorya RC, Wong J, Orr-Walker B, Gamble G. Pituitary Tumors. Epidemiology, Pathogenesis and Management, pp 31-42. Ed. SM Webb. Bristol: BioScientifica Ltd, 1998.

40 Holdaway IM, Rajasoorya RC \& Gamble G. Factors influencing mortality in acromegaly. Journal of Clinical Endocrinology and Metabolism 200489 667-674

Received 9 March 2004

Accepted 9 June 2004 